\title{
Multi-cycle rolled aluminum alloy 3103 sandwiches: mechanical properties and stamp ability
}

\author{
Ekaterina Nosova ${ }^{1, *}$, Yaroslav Erisov ${ }^{2}$, and Fedor Grechnikov ${ }^{2}$ \\ ${ }^{1}$ Samara University, Metal Technology and Aviation Material Science Department, 443086, Moskovskoye shosse, 34, Samara, Russia \\ ${ }^{2}$ Samara University, Metal Pressure Working, 443086, Moskovskoye shosse, 34, Samara, Russia
}

\begin{abstract}
Constructional part producing by sheet stamping of multilayer composites requires the stamping ability data. The aim of a work is to estimate mechanical properties, stamping ratio and anisotropy indexes of 2, 4, 8 and 12 layer sandwiches produced from aluminium alloy AA3103. The pieces were received by the cold rolling. Interoperation annealing was at $500^{\circ} \mathrm{C}$ for 1 hour. Charts of tensile strength, yield stress, elongation depending on layer thickness were composed. It was found that cold strain hardening does not disappear after annealing if the foil's thickness become $0.4 \mathrm{~mm}$ and less. Microstructure analysis has shown a good contact between layers for all samples and thicker outer layers.
\end{abstract}

\section{Introduction}

Multilayer rolling is one of popular processes for the fine structured materials producing including nano scale materials [1]. Initial alloys have to be very ductile to allow a high reducing ratio for a diffusion welding of separate layers $[2,3,4]$. For this reason joining of sheets is performed in hot state or additionally assisted by electricity, impulse magnetic etc. [5,6]. But heating can lead to recrystallization and disappeared borders between single foils [7].

Absent borders may decrease fatigue strength of a final construction part [8]. Aluminium alloys have a high ductility in cold and heated condition but low strength. Aluminium alloy AA3103 is used for welded tanks, petroleum and oil transport tubes, radiators and another constructional parts and links. Using a multilayer structure these parts may have a higher fatigue especially during cyclic load in comparison to compact material [9].

Presence of a strength oxide film on the sheet surface defenses alloys from corrosion and can be used as reinforcement bodies in aluminium matrix in the layer composites at cold rolling joining [10]. The thinner layers of produced composite lead to more bulk part of the oxide phase therefore the strength is higher and ductility is less. This composition of properties makes a difficulty at sheet stamping of layer composite sandwiches [11, 12]. However, at present there are ways of stamp ability increasing due to rational texture set in aluminium alloys, which are published by authors of this work. The aim of present work is to produce of multilayer sheets from aluminium alloy AA3103 and to research their mechanical properties and stamp ability.

\section{Experimental procedure}

The commercial aluminium alloy AA3103 sheet with 1 $\mathrm{mm}$ thickness was used as initial blanks for producing multilayer specimens. At a first step pieces were cut to $250^{\times} 70^{\times} 1 \mathrm{~mm} 3$ and annealed at $500^{\circ} \mathrm{C}$ for 1 hour in muffle furnace. Then one plain side of the samples was scratched for roughness with a metallic brush at the angle $\approx 45^{\circ}$ to a rolling axis and alcoholic treated for a fat removing. Pare of the samples was gathered with a faced scratched side inside and front edge of sandwich was joined to prevent a displacement by adhesive making a line dots with a distance nearly $10 \mathrm{~mm}$ between them. After that, sandwich was rolled with a thickness reducing degree 55$60 \%$. Further samples were annealed at $500^{\circ} \mathrm{C}$ for 1 hour for softening. Procedure of metallic brush scratching, joining and cold rolling was repeated. Thereby the 2, 4, 8 and 12 layer samples were made. A thickness of sandwich and single layer after each pass of cold rolling are presented at table 1 .

Table 1. Thickness of sandwiches and single layer after cold rolling

\begin{tabular}{|l|l|l|l|l|}
\hline $\begin{array}{l}\mathrm{Nu} \\
\mathrm{mbe} \\
\mathrm{r} \text { of } \\
\mathrm{a} \\
\text { pass }\end{array}$ & $\begin{array}{l}\text { Initial } \\
\text { thickness, } \\
\mathrm{mm}\end{array}$ & $\begin{array}{l}\text { Final } \\
\text { common } \\
\text { thickness, } \\
\mathrm{mm}\end{array}$ & $\begin{array}{l}\text { Numbe } \\
\mathrm{r} \text { of } \\
\text { layers }\end{array}$ & $\begin{array}{l}\text { Expected } \\
\text { average } \\
\text { single layer } \\
\text { thickness, } \\
\mathrm{mm}\end{array}$ \\
\hline 1 & 2 & $0.8 \ldots 0.9$ & 2 & $0.4 \ldots 0.45$ \\
\hline 2 & $1.6 \ldots 1.8$ & $0.72 \ldots 0.96$ & 4 & $0.24 \ldots 0.36$ \\
\hline 3 & $1.92 \ldots .88$ & $0.86 \ldots 1.15$ & 8 & $0.11 \ldots 0.14$ \\
\hline 4 & $2.88 \ldots 4.32$ & $1.29 \ldots 1.73$ & 12 & $0.11 \ldots 0.14$ \\
\hline
\end{tabular}

After rolling and annealing samples for uniaxial tensile test were cut from the panels in along and across direction to the rolling axis. Data of tensile strength, yield stress, elongation were received and charts of their

\footnotetext{
*Corresponding author: eanosova@mail.ru
} 
dependence from layer thickness were made. Also, a stamping ratio $n=\sigma_{0,2} / \sigma_{\mathrm{b}}$ and anisotropy indexes $(\%)$ were calculated by formulae:

$$
\begin{array}{r}
A_{\sigma b}=100 * \frac{\sigma_{b 0}-\sigma_{b 90}}{0.5\left(\sigma_{b 0}-\sigma_{b 90}\right)} \\
A_{\sigma 0.2}=100 * \frac{\sigma_{0.20}-\sigma_{0.290}}{0.5\left(\sigma_{0.20}-\sigma_{0.290}\right)} \\
A_{\delta}=100 * \frac{\delta_{0}-\delta_{90}}{0.5\left(\delta_{0}-\delta_{90}\right)}
\end{array}
$$

here $\sigma_{\mathrm{b} 0}, \sigma_{\mathrm{b} 90}$ - tensile strength $(\mathrm{MPa})$ of along $(0)$ and across (90) samples, $\sigma_{0.20}, \sigma_{0.290}$ - yield stress $(\mathrm{MPa})$ of along and across samples, $\delta_{0}, \delta_{90}$ - elongation ( $\%$ ) of along and across samples.

Microstructural analysis was provided to illustrate contact state between layers and to evaluate the thickness of layers. For this purpose a polished sample was cut along the rolling axis. Etching was during 2 minutes at $20^{\circ} \mathrm{C}$ in solute consisted of $\mathrm{HNO}_{3}-180 \mathrm{ml}, \mathrm{HF}-30 \mathrm{ml}$, $\mathrm{H}_{2} \mathrm{O}-180 \mathrm{ml}, \mathrm{HCI}-180 \mathrm{ml}$. After etching sample was washed under water flow and dried with a soft paper. Research of microstructure was made by optical microscopy using AXIOVERT microscope.

\section{Results}

\subsection{Mechanical properties}

Dependence of tensile strength, yield stress and elongation from a single layer thickness are presented in fig. 1-3.

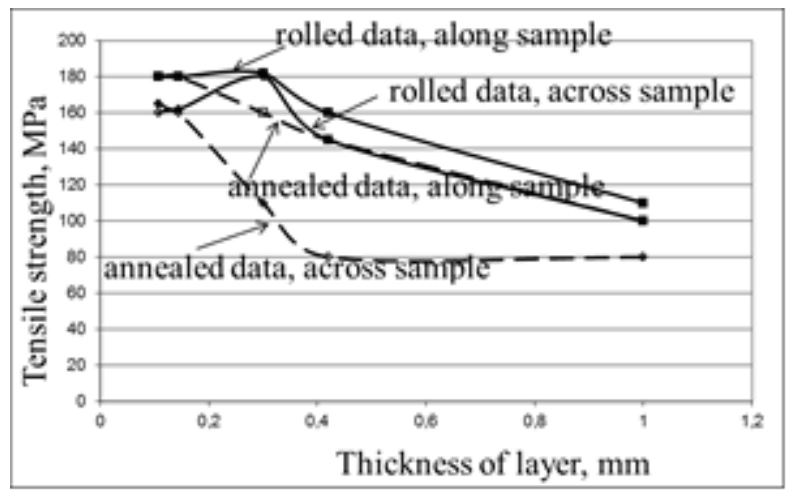

Fig. 1. Charts of the tensile strength depending on the layer' thickness

From fig.1, the along samples' tensile strength grows with the thickness reduce at the cold rolled state and achieves the highest value at the thickness of nearly 0.3 $\mathrm{mm}$. Further reducing of a thickness does not lead to increasing of the tensile strength. Annealing of along samples results to a tensile strength decrease on nearly $10-$ 12 percent for all thickness values, but at thickness of $0.12-0.14 \mathrm{~mm}$ there is no a difference between tensile strength data of annealed and cold rolled state. Across samples do not show the tensile strength growth until thickness reduces from 1 to $0.4 \mathrm{~mm}$. Then tensile strength significantly goes up at both (rolled and annealed) state and takes the greatest values, equal to along samples at cold rolled state, at the thickness of single layer $0.3 \mathrm{~mm}$. When thickness achieves $0.12-0.14 \mathrm{~mm}$ the across samples' thickness have the uniform values and annealing does not lead to decreasing of the tensile strength.

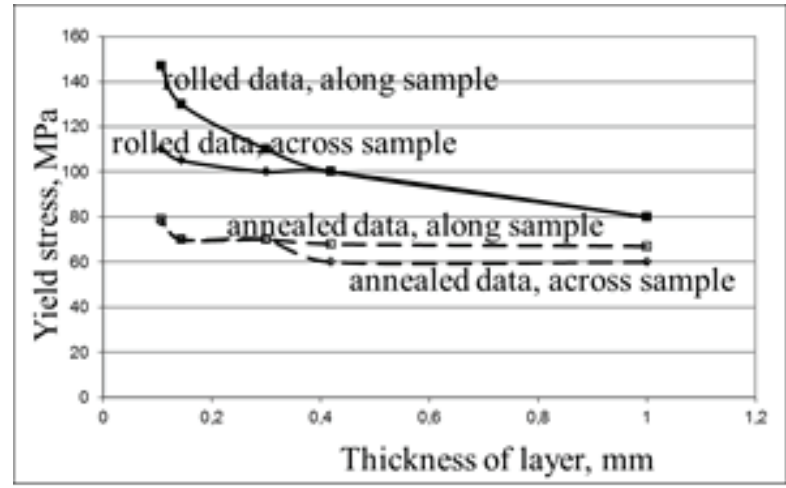

Fig. 2. Charts of the yield stress depending on the layer' thickness

Fig. 2 shows yield stress grows if the layer thickness goes down. If the thickness of single layer at cold rolled state changes from 1 to $0.4 \mathrm{~mm}$ values of across and along samples at rolled state are equal. Then the thickness becomes less, the difference between values of yield stress becomes more obviously. Difference between yield stress values for along and across samples at annealed state is not very large as for cold rolled state, but difference between cold rolled and annealed state becomes more significantly for along samples with the single layer thickness reduces.

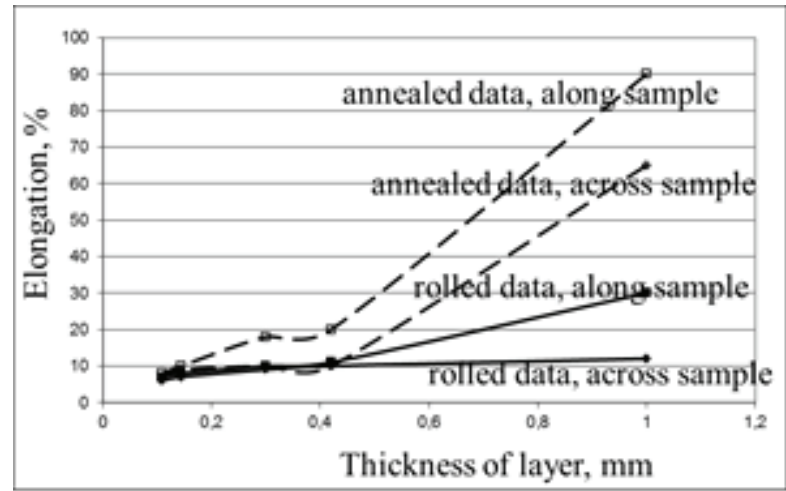

Fig. 3. Charts of the elongation depending on the layer' thickness

Elongation of samples reduces with the single layer thickness goes down (fig.3): the less single layer thickness gives the less elongation. Therefore ductility reduces while foil becomes thinner. The along samples seem to be the most ductile at annealed state. The rest type of samples shows elongation not higher than $10 \%$ if layer' thickness is $0.12-0.4 \mathrm{~mm}$. 


\subsection{Stamping ratio}

Stamping ratio $n=\sigma_{0.2} / \sigma_{b}$ of along samples at rolled state decreases if the layer' thickness become thinner from 1 to $0.3 \mathrm{~mm}$, but for thinner layers $(0.12 \ldots 0.3 \mathrm{~mm})$ this indexes rises (fig.4).

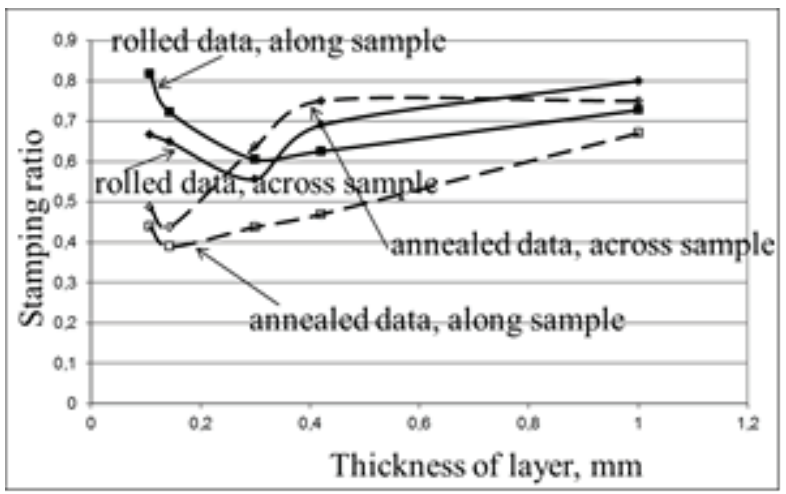

Fig. 4. Charts of the stamping ratio depending on the layer' thickness

For across samples the stamping ratio goes slightly up if the layer thickness moves from 1 to $0.4 \mathrm{~mm}$, then stamping ratio drops until the thickness achieves nearly $0.3 \mathrm{~mm}$ and after that goes up again. Therefore the best stamp ability of samples becomes at the layer' thickness nearly $0.3 \mathrm{~mm}$ at the cold rolled state. Annealed along samples show continuously going down of stamping ratio with layer' thickness reduces. Across samples does not change the stamping ratio in the layer' thickness interval of $0.4 \ldots 1.0 \mathrm{~mm}$. The less than $0.4 \mathrm{~mm}$ down to $0.12 \mathrm{~mm}$ layer' thickness leads to the less stamping ratio. Therefore the thinner foils give the better stamp ability.

\subsection{Anisotropy indexes}

Anisotropy indexes (fig. 5) shows that tensile strength difference between along and across samples at rolled state keeps continuous values if layer thickness reduces from 1 to $0.4 \mathrm{~mm}$.

In the interval of layer thickness there is a gap of anisotropy and at layer thickness $0.12-0.14 \mathrm{~mm}$ values of the strength anisotropy come back to values $10-11 \%$ as for thickness 0.4-1.0 mm.

For annealed state the strength anisotropy index rises with layer' thickness reduces from 1 to $0.4 \mathrm{~mm}$. The thinner foils have the less anisotropic tensile strength. A behaviour of the yield stress at cold rolled state keeps low constant values for foil's thickness of 0.4-1.0 mm. Then yield stress anisotropy rises with foil's thickness reduces.

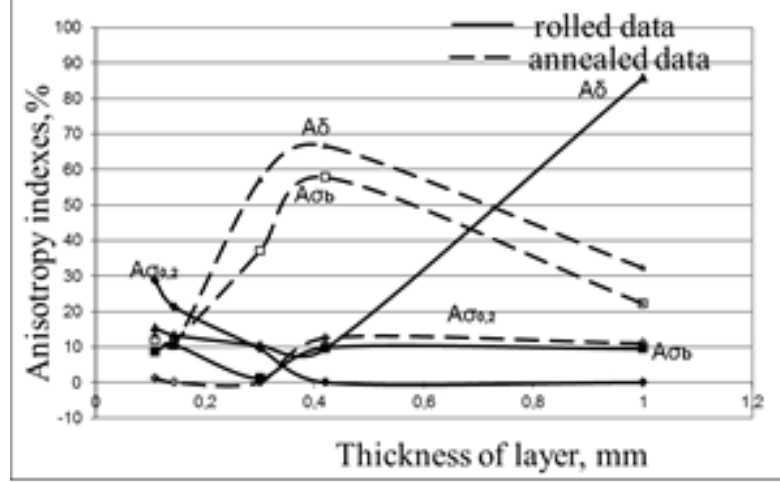

Fig. 5. Charts of the anisotropy indexes depending on the layer' thickness

At annealed state the foiled sandwiches are more anisotropic but stay continuous at the same thickness 0.4$1.0 \mathrm{~mm}$. Thinner foils become less anisotropic. The elongation at cold rolled state decreases the anisotropy until thickness achieves $0.4 \mathrm{~mm}$ from $1.0 \mathrm{~mm}$ and after that slightly goes up for the thinner foils. At annealed state elongation shows increasing of anisotropy with reducing of foil's thickness until $0.4 \mathrm{~mm}$. Thinner foils trends to have more isotropic elongation. Therefore the foil's thickness seems to be a critical value for mechanical properties' anisotropy.

\subsection{Microstructure of sandwiches}

Fig. 6 shows a micro structure of two-layer (a), four-layer (b) and twelve-layer (c) samples.

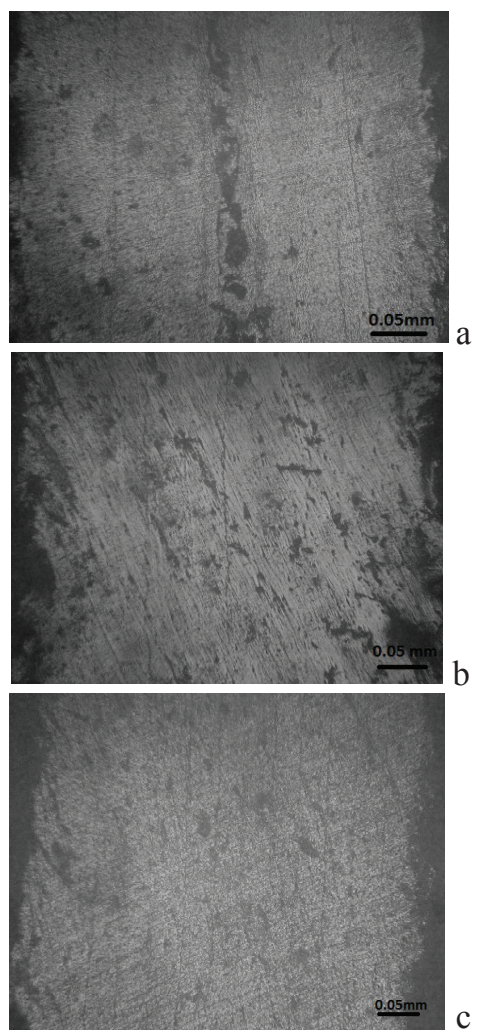

Fig. 6. Microstructure of sandwiches: (a) two-layer, (b) fourlayer, (c) twelve-layer 
It can be seen that there is some delamination in two layer sandwich and there is no delamination of layers in four and twelve layer sandwiches. Thickness of layers is homogeneous and equal but the outer layers are thicker than inner layers. It can be seen more obviously for four layer sandwich (fig.6. b).

\section{Discussion}

Received data shows that common reducing ratio 110 $120 \%$ leading to layer thickness $0.4 \mathrm{~mm}$ after second pass of rolling does not allow to eliminate the cold-hardening during annealing. Thin foils with a thickness 0.12-0.14 $\mathrm{mm}$ have a high tensile strength. Moreover across and along samples do not significantly differ at the rolled and annealed condition.

Very close values of a yield stress for across and along samples at cold state keep a similar behaviour at annealed condition. Loss of yield stress after annealing take place for all reducing ratio and layer thickness.

Elongation decreases with the foil's thickness reduces at rolled and annealed condition excepting along samples. Although elongation decreases and stays very low for the layer thickness $0.12-0.4 \mathrm{~mm}$, its values twice higher than values for another states. Despite a low ductility for thin foils sandwiches, stamping ratio appears very low for 8and 12-layer samples with a foil's thickness $0.12-0.14 \mathrm{~mm}$ due to yield stress loss and keeping high values of the tensile strength. Results of research [10] shows the tensile strength of the reference cold rolled pure aluminium foil having thickness $14 \mathrm{mkm}$ is nearly $35 \mathrm{MPa}$ and common elongation $2 \%$ and $52 \mathrm{MPa}$ and $3.5 \%$ respectively for tensile strength and elongation of the foil at heat treated (annealed at $425^{\circ} \mathrm{C}$ during $7 \mathrm{~min}$ ) state.

Low values of a stamping ratio shows a better stamp ability that is why the most thin foil's sandwiches demonstrates good stamp ability and less elongation anisotropy.

Anisotropy indexes shows more anisotropic behaviour of mechanical properties at annealed state in comparising to the cold rolled state. The anisotropic annealed behaviour can be explained by more ductility after annealing due to opportunity of dislocation sliding. But at the foil's thickness is less than $0.4 \mathrm{~mm}$, ductility goes down because distance of a dislocation developing become short and not enough for sliding. This model is described by Costache et al. in [13]. Borders of layers which are observed on fig. 6 become a barrier for further dislocation move. Microstructure of welded layers of aluminium alloy AA6111-T4 in [14] shows a fine grain structure on the interfacial surface. This area seems to be as a border with a higher strength which limits the plastic deformation. Therefore opportunity for cold-hardening reduces due to a dislocation density growth and ductility becomes limited, as proved by Lederer., Kunčick et al. [9, $15]$.

\section{Conclusions}

1. Reducing of the foil's thickness until $0.4 \mathrm{~mm}$ at packed cold rolling Of AA3003 sheets leads to strength growth. Moreover annealing at $500^{\circ} \mathrm{C}$ for 1 hour does not allow softening for sandwiches which single layers have the thickness less than $0.4 \mathrm{~mm}$.

2. Despite low ductility of thin-foil's sandwiches their stamping ratio takes the lowest values and good stamp ability for samples which foils have the thickness 0.12 $0.14 \mathrm{~mm}$.

3. Anisotropy indexes at annealed state have a trend to decrease if the foil's thickness achieves values $0.4 \mathrm{~mm}$ and less. The cold rolled sandwiches keep a constant anisotropy of strength properties if the foil's thickness is in the interval $0.4 \ldots 1.0 \mathrm{~mm}$. The thinner foils give a higher anisotropy of the yield stress.

Obtained results can be used for further reducing of layers thickness and multiplying of them in composite, studying of the grain structure and the distribution of reinforcing particles such as ceramics and intermetalisc. Also is in plan to obtain multilayer composites from rich alloyed aluminium alloys.

\section{References}

1. M.Lipińska, L.Olejnik, A.Pietras, A.Rosochowski, P.Bazarnik, J.Goliński, T.Brynk, M.Lewandowska, Mater. Des., 88 (2015)

2. R.Kebriaei, I.N.Vladimirov, S.Reese, J. Mater. Process. Technol.., 214 (2014)

3. U. Dilthey, Encyclopedia of Materials: Science and Technology (Elsevier, Amsterdam, New York, 2001)

4. X.Liu, X.-H. Liu, M. Song, X.-K. Sun, L.-Z. Liu, Trans. Nonferr. Met., 26 (2016)

5. M.-K.Ng, L.Li, Zh.Fan, R.X. Gao, E.F. Smith III, K.F.Ehmann, J.Cao, CIRP Ann.-Manuf. Tecchn., 64 (2015)

6. L.Kunčická, R.Kocich, P.Král, M.Pohludka, M.Marek, Mater. Lett., 180 (2016)

7. M.-N.Avettand-Fènoël, G.Racineux, L.Debeugny, R.Taillard, Mater. Des., 98 (2016)

8. A.Diehl, U. Engel, M.Geiger: 4M 2006 - Second Intern. Conf. on Multi-Material Micro Manufacture (2006)

9. M. Lederer, V. Gröger, G. Khatibi, B. Weiss, Mater. Sci. Eng., A 527 (2010)

10. J. Singha, A. Chauhan, Ceram. Int., 42 (2016)

11. Y.Birol: Eng. Fail. Anal., 28 (2013)

12. S. Cottrino, P. Viviès, D. Fabrègue, E. Maire, Acta Mater., 81 (2014)

13. E.M. Costache, N. Nanu, B. Chirita, G. Brabie, Int. J Mech. Sci., 69 (2013)

14. F. Haddadi, D. Tsivoulas, Mater. Charact., 118 (2016)

15. L. Kunčick, R. Kocicha, P. Kral, M. Pohludka, M. Marek, Mater. Lett., 180 (2016) 